\title{
On the Pre-demonstrative (hoti) Conception of Lunar Eclipse in Posterior Analytics B 8
}

\author{
Wellington Damasceno de Almeida
}

My aim is to show that, in Posterior Analytics B 8, the conception of lunar eclipse brought about by pre-demonstrative knowledge (hoti) is deeply vague and radically different from the one obtained by demonstrative knowledge (dioti).

\section{Introduction}

At the controversial chapter 8 of Book B of the Posterior Analytics (hereafter APo), Aristotle presents a new approach to the set of problems discussed in the puzzling chapters 3-7, concerning the relations between definitions and demonstrations. At the last paragraph, a list of results (presumably) achieved along the chapter is provided:

[...] it has been said $(a)$ how the what it is is grasped and comes to be known, so that $(b)$ neither syllogism nor demonstration of the what it is comes to be, although (c) it becomes clear through syllogism and demonstration. Therefore, $(d)$ neither is possible to know the what it is (from which the cause is other) without demonstration $\left(b^{\prime}\right)$ nor there is demonstration of it, $(e)$ as we have said in the puzzles (APo B 8, 93b15-20).

The clause $a$ announces, in general lines, the main result (presumably) achieved by the chapter; $c$ seems to explain $d ; b$ ' repeats $b$. As alluded by $e$, in the so-called "puzzles" (chapters 3-7), $b$ and $d$ were taken to be incompatible. Nevertheless, Aristotle concludes B 8 assuming that both are true, indicating his commitment to a comprehension of $b$ and $d$ according to which the incompatibility was merely apparent. ${ }^{1}$ Indeed, such an incompatibility can be avoided by assuming that $b$ applies only to accounts belonging to the second one among the four types of definition listed in APo B 10 (logos ho dêlôn dia

\footnotetext{
${ }^{1}$ The inconsistency can be avoided by assuming that $b$ applies only to accounts belonging to the second one among the four types of definition listed in APo B 10 (logos ho dêlôn dia ti estin, 93b39), which are called "syllogistic definitions" by Deslauriers (2007).
} 
Journal of Ancient Philosophy ISSN 1981-9471 - FFLCH/USP www.revistas.usp.br/filosofiaantiga
J. anc. philos. (Engl. ed.), São Paulo, v.13, n.2. p. 96-108, 2019. DOI: http://dx.doi.org/10.11606/issn.1981-9471.v13i2p96-108

ti estin, 93b39) $)^{2}$, an assumption supported by Aristotle's explicit restriction of $d$ to those objects mentioned at APo B 9, whose cause is different ${ }^{3}$ (heteron ti aition). Its incompatibility with $b$, of course, is not the only difficulty in which $d$ is involved. As noted by Barnes (2002, p. 212), it is far from being clear how Aristotle obtains $d$ along the chapter:

Strongly construed, this claim <"Without a demonstration you cannot get to know what something is" $>$ is entirely unsupported: $B 8$ has done nothing to show that we can only come to grasp a definition by first constructing an appropriate demonstration.

It is not my purpose to offer a comprehensive interpretation of $A P O \mathrm{~B} 8$. Instead, my aim is to catch attention to some consequences of $c$ on what is granted by the knowledge of that (hoti) in APo B 8. In fact, given that what certain things are, according to $c$, become clear (only) by demonstration, it is reasonable to expect that, for Aristotle, $\left(c^{*}\right)$ without their corresponding demonstrations, what those things are, in some sense to be specified, is unclear. Consequently, the pre-demonstrative knowledge (hoti) of the lunar eclipse brought about in APo B 8 (93a39-93b3) has to presuppose an unclear conception of this astronomical phenomenon. Facing this scenario, I intend to show that the conception of lunar eclipse presupposed by the pre-demonstrative knowledge (hoti) in $A P o$ B 8 is deeply vague and distinct from the one achieved by demonstration.

\section{Unclear demonstrandum}

As already said, there seems to be an explanatory link connecting the clauses $c$ and $d$ in the last paragraph of $A P o$ B 8: $(d)$ it is not possible to know what something is without demonstration because (c) what something is becomes clear through demonstration. Aristotle seems to think that, before obtaining the relevant demonstration, an astronomer, for example, would never know what a lunar eclipse is, except in an unclear manner. Presupposed by $c$, this unclear manner seems to correspond to the type of knowledge

\footnotetext{
${ }^{2}$ Deslauriers (2007) calls those accounts "syllogistic definitions", since their definientia can be converted into syllogisms.

${ }^{3}$ On the question of knowing whether Aristotle has in mind items whose cause is different from the essence or from the substance, see Bronstein (2016, p. 134-137), Charles (1991, p. 236-238) and Chiba (2012, p. 193).
} 
Journal of Ancient Philosophy ISSN 1981-9471 - FFLCH/USP www.revistas.usp.br/filosofiaantiga
J. anc. philos. (Engl. ed.), São Paulo, v.13, n.2. p. 96-108, 2019. DOI: http://dx.doi.org/10.11606/issn.1981-9471.v13i2p96-108

alluded by Aristotle in 93a22, according to which the scientist knows merely some features of the investigated object or "something of the thing" (ti autou tou pragmatos). Commenting on this imprecise and pre-demonstrative knowledge, Barnes (2002, p. 218) briefly suggests the examination of two other texts that could help us to understand what Aristotle could have in mind:

It seems, then, that the 'something' (93a22) which we grasp must be a part of the essence of the object. Met. Z 17, 1041b2-9, and H 4, 1044b 9-15, suggest that the 'something' is the matter of the object, and that we are still in search of its form; alternatively, we might take the 'something' for the kind or genus of the object, and think that we are still in search of its difference.

As well observed by Barnes, the mentioned passage of Metaphysics Z 17 (specially its final lines) suggests that, for Aristotle, the formal component of the hylemorphic explanandum is the essence of the item under investigation and, one presumes, something not (fully) known when the why-question concerning its hylemorphic unit with the material component emerges. Here is how Bostock (2003) translates the relevant statement:

So what is sought is the cause by which the matter is so-and-so, i.e. the form. And that is the substance (Metaphysics Z 17, 1041b7-9).

The relations between APo B 8 and Metaphysics Z 17 are certainly of interest. However, they are not the topic on which I want to focus in the present text. Instead, the connection between the pre-demonstrative knowledge of APo B 8, also known as the knowledge of that (to hoti), and the mentioned passage of Metaphysics H 4 (1044b9-15), already pointed out also by Oswaldo Porchat (2000, p. 323, footnote 202), consists on the interpretative path to be explored hereafter.

Metaphysics $\mathrm{H} 4$ and APo B 8 do not give attention to the same type of objects. $\mathrm{H}$ 4 deals with the appropriate matter to each thing and discusses some cases devoid of a genuine material cause, to which something analogous plays the role of hypokeimenon. ${ }^{4}$ APo B 8 deals with those objects "from which the cause is different" and the definition, although indemonstrable, becomes known exclusively through demonstration. Nevertheless, there is an intersection between these two different domains, on which lays

\footnotetext{
${ }^{4}$ On the two ways of being a hypokeimenon, see Metaphysics Z 13 (1038b4-6) and Code (2015, p. 23-24).
} 
Journal of Ancient Philosophy ISSN 1981-9471 - FFLCH/USP www.revistas.usp.br/filosofiaantiga
J. anc. philos. (Engl. ed.), São Paulo, v.13, n.2. p. 96-108, 2019. DOI: http://dx.doi.org/10.11606/issn.1981-9471.v13i2p96-108

one of Aristotle's favorite cases of demonstrable objects, the lunar eclipse. The relevance of $\mathrm{H} 4$ to APo B 8, however, does not end here. In H 4, Aristotle employs, with some adaptations, his hylemorphic analysis to the case of the lunar eclipse ${ }^{5}$ and asserts that the account (logos) of the form-like ${ }^{6}$ of the lunar eclipse (i.e. the privation of light), somehow, is unclear (adêlos) until it is tied to the explanans (i.e. the interposition ${ }^{7}$ of the Earth between the Sun and the Moon). According to Aristotle:

[i] The <cause> qua form is the account; however, [ii] the account < privation of light'> is

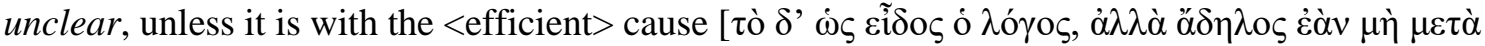

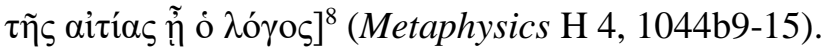

This passage of $\mathrm{H} 4$ seems to involve the same presupposition carried by the clause $c$ in APo B 8. Since (c) what something is, according to APo B 8, becomes clear (only) through demonstration, $\left(c^{*}\right)$ what something is, somehow, is unclear without demonstration. In turn, [ii] since the account (logos) of the form-analogue of the lunar eclipse (i.e. "privation of light"), according to $\mathrm{H} \mathrm{4}$, is unclear, unless it is with the (efficient) cause, $\left(c^{*}\right)$ what the lunar eclipse is, somehow, is unclear without the cause and, thereby, without a demonstration. Thus, to some extent, by mean of the clauses $i$ and $i i$ in $\mathrm{H} 4$, Aristotle corroborates the expectation generated by the clauses $c$ and $d$ in APo B 8, namely, $c^{*}$. Additionally, the clause $i i$ may explain $b$ : (c) what $X$ (e.g. the lunar eclipse) is becomes clear only through demonstration because $(i)$ the logos of the form of $X$ (in the case of the lunar eclipse, the privation of light), without the cause (and, therefore, without demonstration), is unclear (adêlos). That is why Barnes goes to the point of saying that "we are still in search of its form". Porchat (2000, p. 323 and footnote 202), commenting on APo B 8 (93a36-93b2), more precisely, on pre-demonstrative knowledge

\footnotetext{
${ }^{5}$ In fact, the phenomenon of lunar eclipses and sleepiness are peculiar examples, since they do not involve a genuine material cause, but something analogous. For an accurate reconstruction of this chapter, see Code (2015).

${ }^{6}$ Aristotle refers to the privation of light as "to hôs eidos". Hereafter, I employ Code's expression "form-analogue" to refer to it.

${ }^{7}$ Technically, in the Aristotelian cosmology, as pointed out by Code (2015), the Earth does not interpose itself between the Sun and the Moon, since it is stationary.

${ }^{8}$ See Code's translation of the passage: "And [the cause] 'as form' is the account, but the account is unclear unless the [efficient] cause is added" (2015, p. 25). Reale (2004) seems to understand the passage, in his translation, in the same way: "La causa formale è la nozione di eclissi; ma questa $<$ la nozione di eclissi $>$ non risulta chiara se non è accompagnata dalla causa efficiente".
} 
Journal of Ancient Philosophy ISSN 1981-9471 - FFLCH/USP www.revistas.usp.br/filosofiaantiga
J. anc. philos. (Engl. ed.), São Paulo, v.13, n.2. p. 96-108, 2019. DOI: http://dx.doi.org/10.11606/issn.1981-9471.v13i2p96-108

of the lunar eclipse, takes the same direction. He understands that, provided only with pre-demonstrative knowledge (hoti) of the lunar eclipse, the astronomer knows what the lunar eclipse is, but merely in an obscure manner. In order to justify this point, also Porchat evokes H 4, assuming that "privation of light", the linguistic expression or logos of the form of the lunar eclipse, is unclear (adêlos) without the cause (and, therefore, without demonstration). The more detailed examination of Metaphysics $\mathrm{H} 4$ (1044b 915), however, which I know of, belongs to Code (2015, p. 24-25):

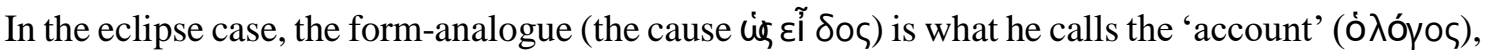
and this is identified as a privation of light.

As can be noted, Code refers to the privation of light not as the form of the lunar eclipse, but as the form-analogue. In order to explain this decision, he points to Metaphysics Lambda 4 (1070b16-21), text in which Aristotle takes the light as being a form and darkness its privation ${ }^{9}$ :

These things then have the same elements and principles, but different things have different elements; and if we put the matter thus, all things have not the same elements, but analogically they have; i.e. one might say that there are three principles - the form, the privation, and the matter. But each of these is different for each class, e.g. in colour they are white, black, and surface. Again, there is light, darkness, and air; and out of these are produced day and night" (Translated by Ross in The Complete Works of Aristotle).

What is relevant, however, is the fact that, like Barnes and Porchat, also Code understands the precise account (logos) described as unclear without the cause in $\mathrm{H} 4$ not as the entire essence of the lunar eclipse, but a certain part of it, namely, the privation of light, which is identified as the cause hôs eidos. This is not the only way of reading $\mathrm{H} 4$

\footnotetext{
${ }^{9}$ In addition, Code also mentions a certain duality of uses of "logos" that is important to keep in mind. In the footnote 35, he says: "Note that in Metaph. $\Lambda 4,1070 \mathrm{~b} 16-21$, light is a form, darkness its privation, and air the matter. In $\mathrm{H} 4$, for an eclipse the form-analogue is a privation. In the case of a substance, he uses the word 'logos' for the account or definition that expresses its form, and sometimes uses it for the form it expresses rather than the linguistic item itself. His use of the term 'logos' has a similar duality of use in connection with definitions of natural phenomena, although in the two examples of eclipse and sleep the causal factor corresponding to a substantial form is not a form, but rather privation. This general characterization of $\sigma \tau \dot{\varepsilon} \rho \eta \sigma 1 \zeta$ needs to be worked out in different ways for different circumstances. For instance, Metaph. @1, 1046a31-35

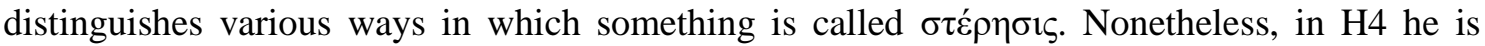
speaking at a high level of generality about causes of natural phenomena, and drawing finer distinctions that do not generalize is not needed for this purpose".
} 
Journal of Ancient Philosophy ISSN 1981-9471 - FFLCH/USP www.revistas.usp.br/filosofiaantiga
J. anc. philos. (Engl. ed.), São Paulo, v.13, n.2. p. 96-108, 2019. DOI: http://dx.doi.org/10.11606/issn.1981-9471.v13i2p96-108

$(1044 b 9-15)^{10}$, but it is the way that fits better with Aristotle's words in that chapter. It is important to note that the form-analogue (i.e. the privation of light) and the efficient cause (i.e. the interposition of the Earth etc.) are respectively the major and middle terms of the demonstration of what the lunar eclipse is (or the items expressed by those terms). In other words, the demonstrandum "the Moon suffers privation of light", untied to its explanans (i.e. the middle term), in some sense, must be unclear (adêlos) too, since its predicate is the form-analogue of the lunar eclipse which is described in $\mathrm{H} 4$ as being unclear. $^{11}$

In order to address an explanation to the clause $i i$, according to which the logos of the form-analogue of the lunar eclipse is unclear, Code (2015, p. 25) appeals to the vagueness or generality of that logos:

Why is the account unclear without the efficient cause? At least part of the reason is simply that without the efficient cause such an account is too general to be something distinctive of just lunar eclipses. There are various ways in which something - even the moon - could be deprived of light.

It seems to me that Code takes the account $(\log o s)$ at issue as being "too general to be something distinctive of just lunar eclipses" in order to give room to the unclearness that affects it, as if being too general and being distinctive of just lunar eclipses would be incompatible. However, the account can be too general and still distinctive of just lunar eclipses. As pointed by Bayer (1995), among the two types of syllogism presented in APo

${ }^{10}$ For a different interpretation, see Bronstein (2016, p. 98): "The formal cause is the whole essence, which must include what Aristotle calls 'the cause' (1044b13, 15) [...]". I do not understand exactly how the formal cause might be the whole essence of the lunar eclipse, since being that the case, the material and efficient causes, one presumes, would be component parts of the formal cause. However, there is a line of interpretation, concerning Metaphysics $\mathrm{Z} \mathrm{17,} \mathrm{that}$ tends to argue in such a direction. On its difficulties, see Bostock (2003, p. 239-242).

${ }^{11}$ It seems, therefore, that not only the Stoic notion of apodeixis, but also the Aristotelian one may involve an unclear conclusion that becomes clear when demonstrated. The commitment to a conclusion that has to be made clear (dêloun) and, thereby, in some sense is unclear, seems to be present in De Anima B 2 (413a11ss.) as well. On the "process of analytic clarification" involved in this passage, see Lesher (2010, p. 152). See also Burnyeat (1981, p.137-138) on the Stoic notion of demonstrative proof (apodeixis): "A demonstrative proof is a valid argument which deduces from premises which are both true and evident a conclusion which in itself is non-evident, where 'evident' and 'non-evident' are strictly epistemic terms paradigmatically illustrated by what is evident or non-evident to sense-perception. The non-evident conclusion is then made known to us by the proof, as in the much-cited example 'If sweat flows through the surface of our bodies, there are insensible pores; sweat does flow through the surface of our bodies; therefore, there are insensible pores"”. 
Journal of Ancient Philosophy ISSN 1981-9471 - FFLCH/USP www.revistas.usp.br/filosofiaantiga
J. anc. philos. (Engl. ed.), São Paulo, v.13, n.2. p. 96-108, 2019. DOI: http://dx.doi.org/10.11606/issn.1981-9471.v13i2p96-108

B 8 (93a35-93b7), one serves to identify the phenomenon under investigation. In the lunar eclipse case, the syllogism concludes that the Moon suffers eclipse, taking as middle term the inability do cast shadows during full moon. This middle term, I presume, is a proprium of the lunar eclipse and, as such, it isolates the occurrences of privation of light that are also of lunar eclipse from those that are not. ${ }^{12}$

To whatever extent, it is important to keep in mind that Metaphysics H 4 (1044b915) carries an implicit comparison between two occurrences of the account $(\log o s)$ of the lunar eclipse: one without the cause (mê meta tês aitias), explicitly pointed out as being unclear (adêlos), and one with the cause (meta tês aitias), whose unclearness, one presumes, is dissipated by its explanatory connection with the cause. Thus, assuming the occurrence without the cause as corresponding to the pre-demonstrative knowledge (hoti) vaguely alluded, this occurrence must be equivalent to that one found in APo B 8 (93a3593b7) and, thereby, seems to involve only synonymous ${ }^{13}$ instances of lunar eclipse. Nevertheless, it remains to be seen in which sense the pre-demonstrative (hoti) conception of lunar eclipse granted in APo B 8 is deeply vague or unclear.

\section{How unclear is this pre-demonstrative knowledge (hoti)?}

At first, it might sound intriguing to take the expression "privation of light" (and its corresponding denotatum, the item it expresses) as being unclear (adêlos). Code, for example, cautiously speaks in terms of an "allegedly" unclear logos. Bostock (2003, p. 275) goes further and tries to correct Aristotle's statement in H 4 (1044b9-15):

It <i.e. the lunar eclipse> also has a formal cause, which is the definition of what an eclipse is. Aristotle recommends us to build into this definition a specification of the efficient cause [...]. He says that unless we do this, the definition will not be 'clear', but that does not seem to be right:

\footnotetext{
${ }^{12}$ Because its middle term is a proprium (idion) of the lunar eclipse (or of an eclipsed moon), the syllogism at issue guarantees all the instances of privation of light under consideration not to be homonymous, but synonymous (in the Aristotelian senses). In other words, they have the same cause (as anticipated by APo B 2, specially 89b37-38 and 90a5-7), implying that they all share the same (still unknown) essence or that they all belong to the same natural kind, as some interpreters prefer. However, it is hard to see how the scientist could recognize such a middle term as being a proprium of the lunar eclipse without knowing its cause, which seems to provide some support to Bolton's (1976) view.
}

${ }^{13}$ Always in the Aristotelian sense. 
Journal of Ancient Philosophy ISSN 1981-9471 - FFLCH/USP www.revistas.usp.br/filosofiaantiga
J. anc. philos. (Engl. ed.), São Paulo, v.13, n.2. p. 96-108, 2019. DOI: http://dx.doi.org/10.11606/issn.1981-9471.v13i2p96-108

the original definition was perfectly 'clear'. What he has in mind, one presumes, is that the expanded definition will give a more informative answer to the question: 'What is an eclipse?'.

Like other interpreters, Bostock tries to deflate Aristotle's statement that the logos of the form-analogue of the lunar eclipse (identified as the privation of light) is unclear (adêlos), preferring to say that it is simply or at most incomplete, but not unclear. Although being cautious to the point of saying that such a $\log o s$ is "allegedly" unclear, Code (2015) takes a different direction, pointing out the curious way by which Aristotle intends to clarify the mentioned logos. According to Code (2015, p. 25):

[...] Aristotle's proposal is not that this $<$ i.e. the unclear $\log o s>$ is clarified by adding some more determinate specification of observable features of the moon's light deprivation, or a fuller phenomenological description of what eclipses look like to observers. The proposal is rather that this (allegedly unclear) logos is made clear by accompanying it with a statement of the efficient cause that is responsible for the subject, the moon, having that property, or form-analogue.

It is surely pertinent to ask why Aristotle's proposal does not consist on "adding some more determinate specification of observable feature of the moon's light deprivation, or a fuller phenomenological description of what eclipses look like to observers". Perhaps, APo B 8 (93b15-20) could help on addressing an explanation. The clause $c$, according to which what something is becomes clear (only) through demonstration, generates the expectation that the essences at issue cannot be made clear unless through demonstration and, thereby, through causal knowledge. Now, causal knowledge might be exactly what Aristotle had in mind when wrote $\mathrm{H} 4$ (1044b9-15) by implicitly suggesting that the logos of the form-analogue of the lunar eclipse becomes clear through its link with the (efficient) cause. In other words, the clause $c$ in APo B 8 suggests that the procedure of clarification of an essence involves demonstrative and, therefore, causal knowledge, which seems to be corroborated in $\mathrm{H} 4$. Certainly, this is not the entire explanation for the curious way, pointed out by Code, by which Aristotle intends to clarify the unclear account of the form-analogue of the lunar eclipse in $\mathrm{H} 4$. The point here is modest and consist in seeing that, under the consideration of the clause $c$, the curious clarification procedure alluded by Aristotle in $\mathrm{H} 4$ becomes less surprising and more expected. A different issue, of course, involves knowing how, for Aristotle, the causal knowledge clarifies that logos.

Nevertheless, the task promised above consists in showing how the logos of the form-analogue of the lunar eclipse (corresponding to the privation of light) can be both 
Journal of Ancient Philosophy ISSN 1981-9471 - FFLCH/USP www.revistas.usp.br/filosofiaantiga
J. anc. philos. (Engl. ed.), São Paulo, v.13, n.2. p. 96-108, 2019. DOI: http://dx.doi.org/10.11606/issn.1981-9471.v13i2p96-108

distinctive of just lunar eclipses and still unclear (or too general). As anticipated, the predemonstrative (hoti) conception of lunar eclipse refers only to synonymous instances of this astronomical phenomenon due to the proprium to which it is tied (i.e. the inability to cast shadows during full moon etc.), which is the middle term of the syllogism alluded in 93a39-93b3. In turn, such a conception, I claim, is deeply vague and maybe to the point of being equivocal. One way of seeing that consists in paying attention to some of Aristotle's presuppositions in APo B 8 (93b3-6). The detailed examination of this text reveals that the pre-demonstrative (hoti) conception of lunar eclipse granted by the syllogism of 93a39-93b3 is radically different from the one granted by demonstrative knowledge. Here is the relevant passage:

However, being granted that 'A' $<$ i.e. eclipse $>$ is predicated of $\mathrm{C}<$ i.e. Moon $>$, to seek 'Why is it predicated?' is to seek 'what is B?': whether it is (1) interposition <of the Earth between the Sun and the Moon> or (2) rotation of the Moon <on its own axis> or (3) quenching <of flames> (APo B 8, 93b3-6).

This text presents a pre-demonstrative (hoti) context in which, for example, the astronomer already knows that the Moon suffers privation of light (eclipse), but does not yet know why it occurs. ${ }^{14}$ The astronomer already knows that the lunar eclipse occurs (or exists), but does not yet know what the lunar eclipse is. That the Moon suffers the precise privation of light also called "lunar eclipse" is granted by the preceding syllogism (93a3593b3), which takes the inability to cast shadows during the full moon as middle term and serves to identify the phenomenon under investigation. ${ }^{15}$ That is why the sentences "the Moon suffers privation of light" and "the Moon suffers eclipse" can be conflated in one

\footnotetext{
${ }^{14}$ On how to understand the Aristotelian distinction between to know that (hoti) and to know why (dioti), I follow Barnes (2002, p. 155): "We might well think we could distinguish between understanding a fact and understanding an explanation in less subtle ways than those Aristotle devises; but in fact Aristotle, despite his language, is not concerned with this distinction at all: rather, he wants to distinguish between understanding a fact 'through' its explanation (i.e. knowing that $P$ on the basis of $Q$, where $Q$ explains why $P$ is the case), and understanding a fact not though its explanation (i.e. knowing that $P$ on the basis of $Q$ where $Q$ does not explain why $P$ is the case). Cases of the second type, which Aristotle divides into two groups, are not, strictly speaking, cases of understanding at all; perhaps with ordinary usage in mind, Aristotle is here countenancing a weaker sense of 'understand' than his official one".
}

${ }^{15}$ Bayer (1995). 
Journal of Ancient Philosophy ISSN 1981-9471 - FFLCH/USP www.revistas.usp.br/filosofiaantiga
J. anc. philos. (Engl. ed.), São Paulo, v.13, n.2. p. 96-108, 2019. DOI: http://dx.doi.org/10.11606/issn.1981-9471.v13i2p96-108

and the same sentence: "the Moon suffers privation of light (eclipse)". In this context, those sentences imply each other. ${ }^{16}$

After introducing the explanandum, that is to say, the fact that the Moon suffers privation of light (eclipse), Aristotle recognizes its three candidates for the role of explanans: (1) the interposition (antiphraxis) of the Earth between the Sun and the Moon, (2) rotation (strophê) of the Moon, and (3) quenching (aposbesis) of the lunar surface's fire. It is not easy to reconstruct all of the details involved in each of the running theories, but some interpretative assumptions can be safely pointed out. Firstly, the explanation 1 presupposes the Parmenidean insight of the heliophotism of the Moon ${ }^{17}$, which implies that $(\beta)$ the Moon is not incandescent. Secondly, the remaining explanations, 2 and 3, do not presuppose the Parmenidean insight. Instead, both are committed to the scrapped hypothesis according to which $(\alpha)$ the Moon is incandescent. Thirdly, Aristotle takes all the three explanations as being genuine answers of one and the same question: $(Q)$ "Why the Moon suffers privation of light (eclipse)?". With these three assumptions in mind, it becomes easier to see how deeply general and semantically poor is the pre-demonstrative conception of lunar eclipse at issue.

In fact, since that, for Aristotle, all the three explanations (1,2 and 3) are genuine answers ascribed to the same question, this pre-demonstrative conception of lunar eclipse, carried by the question $(Q)$ "Why the Moon suffers privation of light (eclipse)?", must be deeply vague to the point of not presupposing neither that $(\alpha)$ the Moon is incandescent nor that $(\beta)$ the Moon is not incandescent, under penalty of producing an inconsistency with some of its answers. In fact, if the question "Why the Moon suffers privation of light (eclipse)?" presupposes $\alpha$, the explanation 1 cannot be a genuine answer. Why not?

\footnotetext{
${ }^{16}$ As it is known, by dealing with the analogous case of thunder in APo B 8 (93b7-12), Aristotle goes as far as substituting the predicate of the sentence "the cloud thunders" for the predicate of the sentence "the cloud makes noise". In fact, identified the phenomenon under investigation, as occurs in APo B 8 (93a35-93b3), to know that the cloud makes noise implies to know that the cloud thunders. Analogously, to know that the Moon suffers privation of light implies to know that the Moon suffers eclipse.

${ }^{17}$ As far as I know, Parmenides is responsible for developing a cosmology in which the Moon was thought to reflect the Sun's light. In doing so, he paved the way for the correct comprehension of the lunar eclipse by Anaxagoras. On the merits of Parmenides, see Graham (2013, p. 156-159): "Parmenides' insight of heliophotism provides the starting point for a set of implications that includes the possibility of explaining eclipses by reference to antiphrasis". On the merits of Anaxagoras, see Burnet (1920, p. 198), Curd (2007, p. 233), and especially Graham \& Hintz (2007, p. 333).
} 
Journal of Ancient Philosophy ISSN 1981-9471 - FFLCH/USP www.revistas.usp.br/filosofiaantiga
J. anc. philos. (Engl. ed.), São Paulo, v.13, n.2. p. 96-108, 2019. DOI: http://dx.doi.org/10.11606/issn.1981-9471.v13i2p96-108

Because the explanation 1 presupposes $\beta$, which is incompatible with $\alpha$. Now, can a question and one of its genuine answers be committed to incompatible assumptions? ${ }^{18}$ The story ends up in the same results when one assumes that the mentioned question presupposes $\beta$ instead of $\alpha$. In such a case, the explanations 2 and 3 cannot be genuine answers, since both presuppose $\alpha$, which is incompatible with $\beta$. In order to avoid any inconsistency involving the question and some of its genuine answers, it is required to assume that the conception of lunar eclipse underlying the pre-demonstrative context of the question $Q$ is too general, to the point of not being committed neither to $\alpha$ nor to $\beta$.

Now, if not unclear (adêlos), what such an intriguing privation of light, called "lunar eclipse", might be for an astronomer who does not yet know its cause? In this context, it is unknown whether the phenomenon at issue is a privation of solar light or of light generated by a flaming Moon that rotates in its own axis or simply quenches from time to time. In short, even the fundamental connection between the intriguing lunar eclipse and the shadow projection phenomena with which ordinary people are familiar is still unknown, so that the pre-demonstrative conception of lunar eclipse at issue cannot be the same as the one provided by demonstrative knowledge, since the last one, among other things, depends on recognizing such a connection. ${ }^{19}$

\footnotetext{
${ }^{18}$ An answer cannot be incompatible with the assumptions of its question. Such a requirement consists of nothing more than a formal condition to be met by any genuine answer (even by those based on false assumptions!). The sentence "The Earth is not in the center of the universe" is not a genuine answer to the question "Why is the Earth in the center of the universe?", but simply the rejection of a presupposition on which the question at issue depends in order to be successful. By stating the sentence, one rejects the presupposition and annihilates the question. In the same direction, see van Fraassen (1980, p. 26).

${ }^{19}$ Some interpreters seem to understand the passage from pre-demonstrative to demonstrative knowledge in similar terms. Charles (2000, p. 45), for example, by comparing the first and the third kind of definition among those listed in APo B 10, points out a "semantic" difference between them: "[...] the first definition is [...] general in form, and fails uniquely to identify the type of noise in question. While it says that thunder is a type of noise in the clouds, it does not state which it is. Thus, the definiens as well as the definienda will be different in the two cases. Even if some of the same terms are used ("noise in the clouds") at Stage 1 they are used to make an indefinite claim about a type of noise (tis), while in the second they uniquely identify the phenomenon in question". The expression "noise in the clouds" is precisely the conclusion of the demonstration of what thunder is (see APo B 10, 94a 8-10), although formulated as a naming expression. Charles seems to think that the same terms (i.e. "noise in the clouds") might be used both in a vague sense (in Stage 1, when the scientist does not know whether or not thunder exists) and in a more precise sense (Stage 3, when the scientist already have scientific knowledge). Ferejohn (2013, p. 144-145) argues in a similar direction, speaking of a "phenomenal (or 'thin') conception of thunder", one that gives place to the scientific conception which is obtainable from a scientific demonstration. Thus, it seems that the scientific demonstration promotes the
} 
Journal of Ancient Philosophy ISSN 1981-9471 - FFLCH/USP www.revistas.usp.br/filosofiaantiga
J. anc. philos. (Engl. ed.), São Paulo, v.13, n.2. p. 96-108, 2019. DOI: http://dx.doi.org/10.11606/issn.1981-9471.v13i2p96-108

Given this scenario, it is hard to see how the pre-demonstrative conception of lunar eclipse in APo B 8, granted by the knowledge of that (hoti), might not be equivocal. Instead, it is easier to see why, without demonstration, it is not possible to know what, for example, the lunar eclipse is. ${ }^{20}$

Wellington Damasceno de Almeida

Universidade Federal de Goiânia

\section{Bibliography}

Angioni, L. Explanation and Definition in Physics I 1. Apeiron 34, 2001: 307-320. https://doi.org/10.1515/apeiron.2001.34.4.307

Barnes, J. Aristotle: Posterior Analytics. Translated with a commentary. Second edition. Oxford: Clarendon Press, 1993.

Bolton, R. Essentialism and Semantic Theory in Aristotle: Posterior Analytics, II, 7-10. The Philosophical Review, vol. 85, no 4, 1976: 514-544. https://doi.org/10.2307/2184277

Bronstein, D. Aristotle on Knowledge and Learning. Oxford: Oxford University Press, 2016.

Burnet, J. Early Greek Philosophy. London: A \& C Black, 1920.

Burnyeat, M. F. Aristotle on Understanding Knowledge, in Berti, 1981: 97-139.

Charles, D. Aristotle on Meaning and Essence. Oxford: Clarendon Press, 2000.

Chiba, K. Aristotle on heuristic inquiry and demonstration of what it is. Oxford Handbook of Aristotle, 2012: 171-201. https://doi.org/10.1093/oxfordhb/9780195187489.013.0008

Code, A. The 'matter' of sleep, in Ebrey, 2015: 11-45.

reinterpretation of the phenomenal data in order to produce the scientific conception. In turn, discussing Physics I 1 (184a16-26), Angioni (2001, p. 319) recognizes the role of explaining in relation to the formulation of new definitions, suggesting that the scientist, by explaining, might be redefining definienda: "Research in the natural science consists exactly in this inquiry into differentiations and exact definitions, and this explains why Aristotle describes it as a path from 'katholou' towards 'kath' hekaston'. According to this itinerary of research, scientific explanation does not consist in a mere inclusion of data in more and more general classes. This work of classification is a mere preparatory step to another kind of work: to discern specific features able to explain why things have the generic features we first are acquainted with and to ground a definition more satisfactory than the preliminary one".

${ }^{20}$ I would like to acknowledge Mateus Ferreira, Breno Zuppolini, Lucas Angioni, Raphael Zillig, Paulo Ferreira, Fernando Mendonça and Marco Zingano for the enriching discussions and helpful suggestions. Additionally, I want to thank CNPq for the financial support for my research project, of which some of the ideas here presented are results. 
Journal of Ancient Philosophy ISSN 1981-9471 - FFLCH/USP www.revistas.usp.br/filosofiaantiga
J. anc. philos. (Engl. ed.), São Paulo, v.13, n.2. p. 96-108, 2019.

DOI: http://dx.doi.org/10.11606/issn.1981-9471.v13i2p96-108

Curd, P. Anaxagoras of Clazomenae: Fragments and Testimonia: A Text and Translation with Notes and Essays. Toronto: University of Toronto Press, 2007.

Deslauriers, M. Aristotle on Definitions. Leiden: Brill, 2007.

Ferejohn, M. T. Formal Causes: Definition, Explanation, and Primacy in Socratic and Aristotelian Thought. Oxford: Oxford University Press, 2013.

Graham, D. \& Hintz, E. Anaxagoras and the Solar eclipse of 478 BC. Apeiron 40 (4), 2007: 319344. https://doi.org/10.1515/apeiron.2007.40.4.319

Graham, D. W. Science before Socrates: Parmenides, Anaxagoras and the new astronomy. Oxford: Oxford University Press, 2013. https://doi.org/10.1093/acprof:oso/9780199959785.001.0001

Lesher, J. H. Saphêneia in Aristotle: 'Clarity', 'Precision', and 'Knowledge'. Apeiron 43, 2010: 143-156. https://doi.org/10.1515/apeiron.2010.43.4.143

Van Fraassen, B. C. A Re-examination of Aristotle's Philosophy of Science, Dialogue, 1980, 19: 20-45. https://doi.org/10.1017/s0012217300024719 